\title{
LAS METAMORFOSIS COMO GÉNERO LITERARIO EN LA ANTIGÜEDAD CLÁSICA Y EN LOS RELATOS DE KAFKA ${ }^{1}$
}

\author{
José RAMÓn DEL CANTO NIETO \\ I.E.S. Madina Mayurqa (Palma de Mallorca) \\ josdelcanto@yahoo.es
}

\section{RESUMEN}

Se establece en el artículo una comparación entre la obra de Kafka Die Verwandlung. (tradicionalmente traducida como La Metamorfosis) así como otros relatos en los que la transformación es de animal a hombre (Informe para una academia y El nuevo abogado) con otras obras del género de las metamorfosis de la antigüedad griega y romana, destacándose la originalidad de Kafka no sólo en sentido técnico, sino, especialmente, en la relación establecida desde antiguo entre culpa y metamorfosis.

PALABRAS ClAVE: Extrañamiento, identificación, transformación, metamorfosis, Cerambo, escarabajo, metáfora, culpa, fantástico, extraño, maravilloso.

\section{ABSTRACT}

A comparison is made between Kafka's work Die Verwandlung (traditionally translated to Spanish as La Metamorfosis) and other stories in which the transformation takes place from animal to man (Informe para una academia and El nuevo abogado) with other works about metamorphosis taken from the Greek and Roman antiquity, underlining Kafka's originality not only in the technical sense, but also in the old relationship between guilty and metamorphosis.

\footnotetext{
${ }^{1}$ Citamos según la edición de Jordi Llovet Franz Kafka. Obras Completas, 1999-2003, en varios volúmenes, Barcelona, ed. Galaxia Gutemberg- Círculo de lectores. Señalamos, junto al título de la obra de Kafka y su fecha de publicación, el volumen de las O.C. seguido de página y nombre del traductor.
} 
KEYwORDS: Strangeness, identification, transformation, metamorphosis, Cerambo, beetle, metaphor, guilt, phantastical, strange, wonder.

porque yo no soy un hombre, ni un poeta, ni una hoja, pero sí un pulso herido que ronda las cosas del otro lado.

F.G. Lorca, Poema doble del lago Edem.

Cuando el hombre se ha enfrentado con la Naturaleza, y especialmente con los animales que la pueblan, se ha encontrado ante la poderosa presencia de lo otro. A partir de esta experiencia, ha nacido en él un sentimiento -el extrañamiento- que ha podido llevarle a una postura doble: a apartar o segregar, o a apartarse y segregarse de aquello que, por ser tan distinto, le inquieta. Pero el hombre ha experimentado también ante los animales una fascinación, de especial importancia cuando ha constatado que lo otro es semejante a él mismo, hecho que ha podido entonces llevarle a establecer con ellos una identificación. La doble respuesta ante lo otro (extrañamiento e identificación), una vez formalizadas, han resultado una fuente de la que han emanado un gran número de creaciones simbólicas. La Mitología y la Literatura han podido de este modo, mediante el simbolismo animal, expresar ideas utilizando imágenes sensibles tomadas de la Naturaleza y ofrecer unos reflejos especialmente esclarecedores, unas iluminaciones insospechadas, al desplegar el complejo juego de espejos en el que los hombres se miran en la imagen de los animales y viceversa ${ }^{2}$. Este doble juego de identificación y diferenciación entre unos y otros puede apreciarse también en las creaciones de metamorfosis, pues en ellas los animales pueden mostrar aspectos puramente humanos (los hombres que fueron), y, al mismo tiempo, dejar al descubierto el animal que, escondido en la madriguera de su intimidad, los hombres son ${ }^{3}$. Sobre el simbolismo establecido entre animales y hombres contamos con valiosas reflexiones desde antiguo ${ }^{4}$.

Franz Kafka otorgó en su obra una gran importancia a los animales, quizá por considerarlos un medio de acceso al hombre ${ }^{5}$. Parece unánimemente aceptada por parte de los estudiosos una estrecha identificación simbólica entre los hombres y los animales en el mundo kafkiano, porque en él, ni los hombres son casi nunca solamente humanos, ni los animales están del todo alejados ni son extraños al comportamiento de la sociedad y de los hombres ${ }^{6}$. Pero, ante todo, los animales sirvieron a Kafka como un recurso de expresión literaria. En este sentido, conviene señalar de entrada que su obra es heredera de motivos y estructuras simbólicas tradicionales. En efecto, «el núcleo del arte narrativo de Kafka» es, según el crítico Jordi Llovet, «el aliento del mito», porque goza de una

\footnotetext{
${ }^{2}$ Sobre este aspecto, en lo referente al mundo griego, véase Darmon, J-P. y Schnapp-Gourbeillon, A.: «El valor semántico del bestiario en la mitología griega», en Bonnefoy, Y. (ed.) 1981, pp. 219-234.

${ }^{3}$ Cf. Brunel (1974: 180-181).

${ }^{4}$ Puede decirse, de manera general, que el juego simbólico-literario se ejerce entre dos planos, los tradicionalmente llamados real e imaginario. Ya Teón (Rhetores graeci II, p. 72, Spengel), en el siglo I ó II d. C., definía la fábula como «un relato fingido que ofrece una imagen de la verdad».

${ }^{5}$ Un resumen de las principales interpretaciones por una parte de la crítica acerca de la significación de los animales en la obra de Kafka puede leerse en W. Falk (1961: 558, n. 28).

${ }^{6}$ Cf. J. Llovet (1990: 9-10) y M. Salmerón (1999: 28-35).
} 
«fuerza evocadora sustancial» ${ }^{7}$; no en vano ejerce su poder sobre «una memoria y unas costumbres colectivas» ${ }^{8}$. Pero, en la escritura kafkiana, «el aliento del mito» acaba adquiriendo unos perfiles particulares, unas significaciones especiales, fruto de una trasgresión calculada de las reglas del arte. Utiliza cristalizaciones literarias, moldes reconocibles, sí, pero alterados de tal manera que sus obras desembocan en una mitología original, nueva, aquella que crea la atmósfera inconfundible -siempre inquietante y fascinante- a la que, por pereza, seguimos llamando kafkiana. Sirva como ejemplo esta $\mathrm{Fa}$ bulilla en la que hablan los animales-hombres (u hombres animales):

«Ay»-dijo el ratón-, «el mundo es cada día más pequeño. Primero era tan ancho que me daba miedo, seguí corriendo y me sentí feliz al ver por fin los muros que se alzaban a lo lejos, a derecha e izquierda, pero esos largos muros se precipitan tan velozmente los unos contra los otros que ya estoy en el último cuarto y allá en el rincón espera la trampa en la que voy a caer. «Tienes que cambiar la dirección de tu carrera», dijo el gato, y lo devoró9.

Sabemos que Kafka era reacio a que se clasificaran sus relatos en los que los animales juegan un papel relevante bajo el epígrafe de parábolas, alegorías o cualquier otro tipo de género literario; prefería títulos más neutros, como Historias de animales ${ }^{10}$. El título de su obra más conocida, La Transformación (Die Verwandlung), traducida tradicionalmente como La Metamorfosis, un título de gran solera literaria en la antigüedad clásica, alude en lengua alemana tan sólo a la idea neutra de «cambio» $\mathrm{o}$ «transformación». Kafka prefirió esta palabra germánica a la de raíz griega Metamorphose, «posiblemente porque deseaba aproximar el sentido de su narración al plano de lo doméstico, lo habitual y lo cotidiano, y porque deseaba alejarlo del plano de lo extraordinario, lo fantástico y lo mitológico» ${ }^{11}$. Pero, a pesar de ello, las leyes artísticas del género de las Metamorfosis siguen conservando en la obra del escritor checo rasgos de forma y contenido, combinados, eso sí, con aquellos conscientemente alterados. Es preciso tener en consideración esta circunstancia para el cabal entendimiento de la originalidad de sus relatos de metamorfosis. Podría decirse, de manera general, que, dentro de la tradición fantástica de las metamorfosis, Kafka se mueve como un artista del trapecio que salta siempre sobre «el otro lado», sobre «el lado insólito» de los términos tradicionales que ofrece el simbolismo. Ello es posible, principalmente, por la especial consideración que hace de los animales y de los hombres en la época en que le tocó vivir, según veremos.

Las metamorfosis, tanto en la mitología clásica como en la literatura de ficción, presentan una gran variedad. Podemos recordar, a un nivel mítico o religioso, el esplendor de los dioses griegos que se manifestaban por su propio poder en distintas formas (animales, humanas, etc), formas de las que podían volver, al cabo del tiempo, para seguir siendo ellos mismos; o de la ascensión de algunos héroes a la categoría de dioses (esta última

\footnotetext{
${ }^{7}$ Llovet (Prólogo a las Obras Completas, III, p. XXX).

${ }^{8}$ Ibid., p. XXXI.

${ }^{9}$ Fabulilla (1920), O.C. III, p. 762. Trad. A. Kovacsics. En esta historia puede percibirse el principio de contradicción: el camino a la libertad y la vida es el camino a la prisión y la muerte. Ello produce la angustia del cazador cazado.

${ }^{10}$ Cf. Llovet (1990: 8). Sin embargo, para W. Benjamin (1938: 207), «las creaciones kafkianas son todas ellas parábolas».

${ }^{11}$ Cf. Llovet (O.C. III, p. 987)
} 
modalidad -la apoteosis-, por la que se pasaba de algo menos que un hombre a algo más que un hombre, era, sin embargo, la menos frecuente) ${ }^{12}$. La inmensa mayoría de las metamorfosis en el arte y la literatura del mundo clásico, sin embargo, expresan principalmente el descenso de un hombre a una naturaleza animal: nos hablan de personajes que, tras una caída (su pecado original), adquieren un nuevo estado; algunos de ellos, tras un penoso camino, tras una serie de pruebas, pueden volver a recuperar su anterior condición humana. Esta vuelta supone entonces una redención. En los cuentos tradicionales podemos encontrar muchas metamorfosis, pero -advierte Rafael Sánchez Ferlosio- sólo de estas dos clases, las definitivas, en las que un ser metamorfoseado permanece en su nuevo estado para siempre, o aquellas en que «la metamorfosis es un estado transitorio de desfiguración del aspecto sensible verdadero, que al final se recupera» ${ }^{13}$. En este tipo, «el paso de peor a mejor es siempre una segunda metamorfosis que deshace otra anterior y, por lo tanto, un retorno, un rescate, una liberación» ${ }^{14}$; por el contrario, «el paso de mejor a peor es siempre, eterno o transitorio, un castigo» ${ }^{15}$. Un ejemplo clásico de metamorfosis de rescate es la de Lucio, el protagonista del relato de Luciano de Samosata (s. II d.C.), Lucio o el asno, y de la novela de Apuleyo (s. II d. C.), El asno de oro ${ }^{16}$, quien, tras haberse convertido en este animal, logra finalmente, tras una serie de pruebas, recuperar su forma humana. El protagonista de la metamorfosis más conocida de la obra de Kafka, Gregor Samsa, por el contrario, una vez transformado en un insecto, no recuperará ya nunca su forma originaria.

Se ha considerado, por otra parte, que el ser resultante de una metamorfosis está ya preludiado en la vida anterior del personaje que acaba transformándose. El hecho de que el ser transformado siga siendo, de alguna manera, el mismo que antes de su metamorfosis, hace posible, en efecto, el establecimiento de un simbolismo entre ambos seres: Una mujer dura de corazón, por ejemplo, puede acabar convertida en una piedra ${ }^{17}$. Otra de una vivacidad extraordinaria, en comadreja ${ }^{18}$. La lubricidad y ambición de Lucio acarrean su conversión en asno, animal que en la antigüedad representaba, simbólicamente, dichas características ${ }^{19}$. Las metamorfosis, tanto en su paso de mejor a peor como de peor a mejor, parecen seguir la máxima de Píndaro: «ihazte el que eres!» ${ }^{20}$. El símbolo o la metáfora establecidos por medio de la metamorfosis participa así de dos planos: es lo mismo y es lo otro; es, a la par, un antes y un después ${ }^{21}$.

Antes de abordar la originalidad de los relatos de metamorfosis de Kafka con respecto a los parámetros del género en la antigüedad, puede resultar útil su comparación

\footnotetext{
${ }^{12}$ Es famoso, en la Mitología griega el caso de Heracles. Ovidio (Met. XV, 745-870) habla de la divinización del alma de César.

${ }^{13}$ R. Sánchez Ferlosio (1972: 15)

${ }^{14}$ Ibid.

15 Ibid.

${ }^{16}$ Ambas obras derivan seguramente de otro texto perdido, según el patriarca bizantino Focio. Véanse las introducciones a las respectivas traducciones de Apuleyo de J. Martos, 2003, y de L. Rubio, 1978.

${ }^{17}$ Es el caso de la leyenda de Anaxárete. Cf. Ovidio, Met. XIV, 698-771 y Antonino Liberal, s.u. Arsínoe, Met. XXXIX.

${ }^{18}$ Es el caso de la leyenda de Galántide. Cf. Ovidio, Met. IX, 306-323, y Antonino Liberal, s.u. Galintíade, Met. XXIX.

${ }^{19}$ Cf. Brunel (1974: 174).

${ }^{20}$ Píndaro, Pítica II, 72.

${ }^{21}$ Cf. Brunel (1974: 180-181).
} 
con una leyenda de la mitología griega, una historia de metamorfosis «clásica» en su género, a pesar de su sobriedad literaria. Se trata de la leyenda de Cerambo, cuyo más antiguo tratamiento se remonta a Nicandro de Colofón, autor y recopilador de relatos de Transformaciones (Heteroioúmena) que vivió en el siglo II a. $\mathrm{C}^{22}$. Ha llegado hasta nosotros gracias a la colección de historias de metamorfosis que realizó Antonino Liberal, un autor de época y nombre romanos que escribió en griego en el siglo II d. $\mathrm{C}^{23}$ : Cerambo, hijo y nieto de dioses ${ }^{24}$, fue un pastor que ocupaba su tiempo en el ejercicio bucólico de la música al pie de los montes de Tesalia. Pasaba por ser el mejor cantor de su tiempo y el inventor de la siringa pastoril; se decía también que fue el primer mortal que tañó la lira y que con su canto hacía las delicias de las Musas. Su felicidad, sin embargo, llegó a su fin en el momento en que, enloquecido por los dioses, no siguió el consejo del dios Pan de trasladar su ganado a otra región más suave cuando ya era inminente un invierno riguroso. Ciego de soberbia (hýbris) se atrevió además a insultar a Posidón y a las ninfas. Cuando se helaron los torrentes y una copiosa nevada cubrió ganado, árboles y senderos, pagó el precio de su delito: Las diosas lo convirtieron en un insecto que Nicandro (o Antonino) se ocupa en describir detalladamente: «Aparece en los árboles, tiene dientes ganchudos y mueve el mentón continuamente; es negro, alargado, de alas duras [en rigor, élitros], parecido a los grandes escarabajos ${ }^{25}$. Esta descripción tan precisa permite la identificación de su especie sin dificultad: Se trata del llamado «ciervo volante» (Lucanus cervus), un escarabajo del que se cree que da saltos como los ciervos, a los que se asemeja por la forma de sus astas ${ }^{26}$. Recibe también el nombre de «buey comedor de leña» por su tendencia a devorarla. Su cabeza se parece además a una lira de caparazón de tortuga ${ }^{27}$. Por último, la leyenda nos informa de un entretenimiento: los niños llevan, a modo de amuleto, su cabeza cortada al cuello, como un juguete que evoca la lira musical ${ }^{28}$, hecho que recuerda en el presente las vicisitudes y desgracias pasadas de Cerambo.

El protagonista de La Transformación de Kafka no goza de una alcurnia divina, sino que se trata de un corriente viajante de comercio que vive con su familia, a la que sostiene. Así como los avatares de Cerambo acaban en una metamorfosis (la leyenda no es sino el preludio de ésta), es precisamente con una metamorfosis como comienza el relato de Kafka, con una frase tan concluyente como difícil de olvidar:

Cuando, una mañana, Gregor Samsa se despertó de unos sueños agitados, se encontró en su cama convertido en un monstruoso bicho ${ }^{29}$.

${ }^{22}$ Cf. Gow y Scholfield (1953: 4-8).

${ }^{23}$ Cf. M. Papathomopoulos, Les Métamorphoses, edición, París 1968, p. IX. La leyenda de Cerambo figura en el capítulo XXII. Ovidio trata también esta historia brevemente (Met. VII, 353-356)

${ }^{24} \mathrm{Su}$ madre era Idotea, una ninfa, y su padre, Eusiro, hijo del dios Posidón. Cf. Antonino Liberal, XXII, 1.

${ }^{25}$ Antonino Liberal, XXII. 6. Trad. J.R. del Canto Nieto.

${ }^{26}$ Entre los tesalios recibe el nombre de kerámbix, nombre derivado de la raíz indoeuropea *ker, que significa «cabeza», «cuerno». Cf. Gil (1959: 50-55; 78-81).

${ }^{27}$ Según la tradición, fue el dios Hermes el primero que fabricó una lira: vació una tortuga y atravesó, perforando el dorso, el caparazón valiéndose de dos cañas en forma de cuernos que sobresalían; a través de ellas tendió una tablilla en forma de puente sobre la que tensó siete cuerdas fijadas al otro extremo del caparazón, el cual servía de caja de resonancia. Cf. Himno homérico a Hermes, IV, 22 y 45 ss.

${ }^{28}$ Cf. Antonino Liberal, XXII. 6.

${ }^{29}$ La transformación (1915), O.C. III, p.87. Trad. J.J. del Solar B. 
Esta última palabra (en alemán Ungeziefer) es más imprecisa que la usualmente traducida como «insecto» (en alemán, Insekt); significa algo así como «bicho» o «bicharraco». Mucho se ha especulado acerca del tipo de bicho en que se ha convertido Gregor; la descripción, a diferencia de la historia de Cerambo, es sumamente imprecisa. Se trata, en primer lugar, de un tipo de artrópodo: «sus numerosas patas, de una deplorable delgadez en comparación con las dimensiones habituales de Gregor, temblaban indefensas ante sus ojos» ${ }^{30}$. Vladimir Nabokov ${ }^{31}$ ha interpretado «numerosas patas» como «seis», multiplicadas por el asombro del protagonista. En tal caso nos hallaríamos, efectivamente, ante un insecto. Pocos datos entomológicos más ofrece el relato: su vientre es oscuro, convexo, surcado por callosidades en forma de arco; dispone además de antenas. La espalda, también abombada, sugiere que guarda unos élitros ${ }^{32}$; tiene fuertes mandíbulas y es capaz de trepar por la pared valiéndose de sus patas, que son viscosas. Aunque tiene la vulnerabilidad de los pequeños insectos, su tamaño, según puede deducirse indirectamente, es el de un perro ${ }^{33}$. Quizá lo más peculiar y metafóricamente significativo sea que está dotado de un duro caparazón ${ }^{34}$ que utiliza a modo de escudo para amortiguar las caídas que efectúa, como entretenimiento, desde el techo. Hay quienes han considerado que se trate de una chinche, insecto del que habla Kafka en su diario poco antes de escribir la obra. Es a propósito de algo que ha oído contar a un compañero de oficina. Dice así:

Su aversión a los insectos. Una vez, por la noche, cuando estaba haciendo el servicio militar, sintió un escozor debajo de la nariz; dormido, llevó la mano hasta allí y aplastó algo. Pero aquel algo era una chinche (Wanze) y durante muchos días paseó por todas partes aquel fétido olor. $^{35}$

Otros han considerado una cucaracha debido a la concordancia que aprecian en el relato entre este insecto y la querencia de Gregor por los sitios oscuros y escondidos, como el cobijo que busca debajo del sofá de su cuarto; pero las cucarachas tienen patas anchas y planas. Para algunos no se trata de un animal repugnante, sino doméstico, como los escarabajos que tenían su madriguera bajo los suelos de madera de las casas de Praga a principios del siglo XX, animales considerados, hasta cierto punto, «parásitos familiares». Aunque el insecto en que se ha convertido Gregor sólo pertenece al reino de la fantasía, ha sido considerado también un escarabajo. En su obra Preparativos de boda en el campo, el protagonista preludia en cierta manera el insecto de la Metamorfosis:

${ }^{30}$ Ibid.

${ }^{31}$ Nabokov (1986: 112)

32 «En los escarabajos, estos élitros ocultan unas finas alitas que pueden desplegarse y transportar al escarabajo por millas y millas en torpe vuelo. Aunque parezca extraño, el escarabajo Gregorio no llega a descubrir que tiene alas bajo el caparazón de su espalda». Nabokov, o.c. p. 112.

${ }^{33}$ En Kafka, «la metamorfosis en algo pequeño se torna más evidente, tangible y verosímil gracias a que el animal, al aumentar de tamaño, se acerca más a nosotros.» Canetti (1968: 187)

${ }^{34} \ll \mathrm{El}$ ansia patética de buscar cierta protección frente al engaño, la crueldad y la suciedad es el factor decisivo para que se formara el caparazón, su escudo de escarabajo, que al principio parece fuerte y seguro, pero que al final se revela tan vulnerable como lo había sido su espíritu y su carne enferma». Nabokov, o.c., p. 115.

${ }^{35}$ Diarios. Cuaderno sexto (18-IX-1912), O.C. II, p. 345. Trad. A. Sánchez Pascual y J. Parra. 
Y mientras estoy acostado en la cama tengo la forma de un gran escarabajo, de ciervo volante (Hirskäfer) o de un abejorro (Maikäfer) ${ }^{36}$, creo yo (...) La forma de un gran escarabajo, sí (...) y apretaba mis patitas contra mi vientre abombado ${ }^{37}$.

Otros, en fin, atendiendo a algunos rasgos peculiares, han querido ver un «escarabajo pelotero (o estercolero)». En efecto, el scarabaeus sacer es un coleóptero negro que fabrica con los excrementos bovinos unas pelotas que lleva rodando hasta su nido. En la habitación de Gregor «aquí y allá se veían ovillos de polvo y suciedad» $»^{38}$, « «también él estaba completamente cubierto de polvo; sobre su espalda y a los lados arrastraba consigo hilos, pelos y restos de comida.» ${ }^{39}$ En un momento avanzado de la obra, la limpiadora de la casa le llama precisamente así $(\text { Mistkäfer })^{40}$. Lo único que parece seguro es que Kafka quiso conscientemente para el insecto una indefinición que penetrara en el mundo subjetivo del lector ${ }^{41}$.

La leyenda de Cerambo es etiológica: la metamorfosis se presenta como una explicación, pues introduce, junto a la causa de la metamorfosis, otra causa secundaria: la del origen del ciervo volante ${ }^{42}$. En La Transformación de Kafka, por el contrario, no es un hombre, como en el caso de Cerambo, quien explica objetiva y racionalmente una especie animal, sino que, como en un espejo inverso, a través de una subjetividad llevada al extremo, a través de una irracionalidad abierta a interpretaciones, es un animal el que explica los distintos aspectos animales en que se ha convertido un hombre, Gregor, y por extensión, la especie humana. La diferencia fundamental entre un relato de tipo nicandreo y uno kafkiano estriba, pues, en el peculiar punto de vista desde el que se consideran los elementos de la metamorfosis. La clave está en la primacía que se establece entre el término real y el imaginario en ambos relatos. Si en el caso de Cerambo el personaje real acaba convertido en un escarabajo (término imaginario) que evoca algún aspecto de su forma o explica metafóricamente algún rasgo del cantor soberbio, en Kafka quedan invertidos estos conceptos: Trata al escarabajo como una metáfora que define, no la forma, sino el carácter esencial del yo de Gregor, y, al tratar el término metafórico imaginario como real, transforma la realidad en una metáfora, de la que el relato pretende ser su explicación ${ }^{43}$. Desde esta perspectiva inversa, es importante señalar, como hace Nabokov, un hecho asombrosamente paradójico: «Gregorio es un ser humano bajo un disfraz de insecto; sus familiares son insectos disfrazados de personas» ${ }^{44}$, ya que la transformación no afecta sólo

${ }^{36}$ A veces se ha traducido como «Escarabajo de Mayo».

${ }^{37}$ Preparativos de boda en el campo (1906-1907), O.C. III, p. 329. Trad. J. J. del Solar B.

${ }^{38}$ La transformación, 1915, O.C. III, p. 126. Trad. J. J. del Solar B.

${ }^{39}$ Ibid. p. 131.

40 «Al principio [la limpiadora] lo llamaba con palabras que probablemente le parecían cariñosas, como « ¿Ven aquí, viejo escarabajo!» o: «¡Caramba con el viejo escarabajo estercolero!» (Seht mal den alten Mistkäfer!).»Ibid, p. 128. Se ha considerado frecuentemente la casi homografía de las tres primeras letras de la palabra escarabajo, Käfer, con el inicio de la palabra Kafka, que además cuenta con el mismo número de letras.

${ }^{41}$ Por ello dijo explícitamente a su ilustrador, Ottomar Starke, en su publicación del año 1915: «El insecto mismo no puede ser dibujado. Ni tampoco puede ser mostrado desde lejos»

${ }^{42}$ La causa secundaria puede considerarse también la primaria. Cf. Brunel (1974: 6-7). Se trata de un tipo de leyendas metonímicas: proponen la explicación de la especie (el todo), a partir de la explicación de la parte (el personaje mitológico).

${ }^{43}$ Cf. Brunel, o.c., p.28.

${ }^{44}$ Nabokov, o.c., p. 140. 
a Gregor, sino a toda la familia. En La transformación ya no hay un antes temporal (como en el caso de Cerambo) que acabe dando cuenta de un ser metamorfoseado: Gregor y el insecto aparecen a la par en la primera frase del relato, y es sólo a medida que avanza la acción cuando se nos explica cómo son el hombre y el insecto, como si las agujas de un reloj marcharan una hacia delante y otra hacia detrás al mismo tiempo. De esta manera, «lo otro» representado por el escarabajo resulta «lo mismo» (y lo mismo, lo otro).

Cuando hablamos de metáfora al referirnos a las metamorfosis en la antigüedad clásica y en la obra de Kafka, nos hallamos ante términos distintos. En la metáfora clásica hay un inequívoco parecido objetivo entre la forma (o conducta) de los personajes míticos y la de los seres transformados. La metáfora kafkiana, por el contrario, es más irracional, y en tal sentido, más moderna. El poeta y crítico Carlos Bousoño ${ }^{45}$ ha llamado «imágenes visionarias» a aquellas imágenes simbólicas en las que la identificación entre un plano real A y un plano imaginario B son percibidas no de un modo lógico o formal, sino a través de una emoción $\mathbf{Z}$. En algunas de estas imágenes, los elementos constitutivos de $\mathbf{B}$ (b1, b2, b3, etc) refuerzan la impresión $\mathbf{Z}$, resultante de la identificación de A y B. Apliquemos este esquema a La Transformación. Ante un principio tan impactante, sin explicaciones previas, que identifica, tras una metamorfosis, a Gregor (A) con un insecto monstruoso $(\mathbf{B})$, el lector experimenta una sensación de extrañeza $(\mathbf{Z})$. Esta emoción presupone algún tipo de analogía que puede percibirse, al menos irracionalmente, a través de las emociones que identifican ambos planos. La «irracionalidad» de la comparación entre un hombre y un insecto puede explicarse en la obra de Kafka, en primer lugar, a partir de la profunda convicción de que la propia interioridad del hombre es desconocida, misteriosa, extraña. El hombre vive en su cuerpo como un extraño. «Quizá ilustre este lado del asunto -dice Walter Benjamin- que Kafka coloque con tanta frecuencia animales en el centro de sus narraciones. Podemos seguir un buen rato sus historias de animales sin percatarnos en absoluto de que no se trata en ellas de hombres. Al topar con el nombre del animal -un ratón o una araña- despertamos asustados y advertimos de una vez que estamos muy lejos del continente del hombre $\gg^{46}$. La eficacia de la identificación profunda entre ambos planos radica, por consiguiente, en una sensación de extrañeza que desemboca en un extrañamiento (apartar o apartarse, segregar o segregarse); así puede percibirse, de manera continua, en las distintas reacciones de los protagonistas ante este insólito hecho. El jefe, la madre, el padre, por ejemplo, reaccionan de la siguiente manera cuando se enfrentan por vez primera con el insecto:

Aún estaba entregado [Gregor] a esa difícil maniobra [abrir la puerta], sin tiempo para pensar en otra cosa, cuando oyó que el gerente lanzaba un fuerte «oh!»-sonó como cuando muge el viento-, y también lo vio, pues era el más próximo a la puerta, taparse con la mano la boca abierta y retroceder lentamente, como impulsado por una fuerza invisible (...) [La madre] miró primero al padre con las manos juntas, dio luego dos pasos hacia Gregor y, hundiendo el rostro en el pecho hasta que desapareció del todo, se desplomó en medio de sus faldas (...) El padre cerró el puño con expresión hostil, como queriendo hacer retroceder a Gregor a su habitación. ${ }^{47}$

\footnotetext{
${ }^{45}$ Bousoño (1976: 186-231, esp. pp. 214-215)

${ }^{46}$ Benjamin (1971: 214-215)

${ }^{47}$ La Transformación, 1915, O.C. III, p. 99. Trad. J. J. del Solar B.
} 
Pero, a todas estas emociones se unen otras en las que se sugiere una identificación entre el hombre y el ser transformado (impotencia, sentimiento de exclusión, indefensión, fragilidad, incomprensión, culpabilidad, etc, por parte de Gregor), que sirven también para explicar la extraña emoción inicial. En efecto, poco a poco, el lector va percibiendo, con un principio de horror, la identificación profunda entre el ser humano y el animal que anida en el interior del hombre. En su desarrollo, las cualidades del plano $\mathbf{B}$ que pueden explicar su identificación con el plano A se le van ofreciendo al lector en un abanico amplio y subjetivo de emociones desde distintos puntos de vista. Esta es, sin duda, una de las razones por las que Kafka quiso conscientemente la imprecisión del insecto: para que se ajustara a las emociones particulares -irracionales y subjetivas- de los lectores.

En cuanto a los asuntos puramente técnicos, las metamorfosis antiguas y modernas pueden coincidir en algunos aspectos. Pueden ser narradas en tercera o en primera persona; «desde fuera» (describiendo objetivamente la forma del nuevo ser), o «desde dentro» (Lucio, por ejemplo, narra sus propias experiencias de conversión en asno). Pero hay algunos rasgos en los relatos de transformaciones de la antigüedad que coinciden con los de las metamorfosis modernas, como es la kafkiana, y resultan un elemento de gran potencial literario: los derivados de la conservación de la conciencia humana en los personajes metamorfoseados ${ }^{48}$. La curiosidad acerca de la posibilidad de la conservación de la conciencia humana tras una metamorfosis en animal es precisamente lo que le lleva al protagonista en el Lucio o el asno a convertirse en animal: «Quería yo aprender por experiencia si, al cambiar externamente mi forma humana, tendría también alma de pájaro» ${ }^{49}$, dice el protagonista después de haber visto a la esposa de su anfitrión convertirse en un cuervo nocturno ${ }^{50}$. El motivo del personaje metamorfoseado que guarda la conciencia de sí mismo es muy antiguo. Homero señala expresamente que los compañeros de Ulises, convertidos por la maga Circe en cerdos, guardaban, sin embargo, su antigua mente de hombres ${ }^{51}$. En los cubiles donde fueron encerrados, lloraban y se alimentaban de bellotas y hayucos hasta que volvieron a recobrar su figura humana. En esta escena homérica se inspiró Ovidio para contar la historia inventada de Macareo, el compañero de Ulises que da cuenta de su metamorfosis una vez recobrado su aspecto humano ${ }^{52}$. Ni uno ni otros podían articular en su nuevo estado un lenguaje humano ${ }^{53}$. El mismo proceso encontramos en personajes como $\mathbf{I o}^{54}$, la hija de Ínaco, la doncella de Argos a la que Júpiter sedujo y posteriormente metamorfoseó en una hermosa ternera blanca a fin de sustraerla a la venganza de su celosa esposa. Pero Juno, que sospechaba el adulterio, se la pidió a su esposo y se la entregó a Argos, el guardián de cien ojos. Una vez muerto el centinela, Juno atormentaba con un tábano a la muchacha, quien, «por sus gemidos, lágrimas y quejumbrosos mugidos pareció que dirigía a Júpiter sus lamentos, pidiéndole el fin de sus

\footnotetext{
${ }^{48}$ Sobre este tema, véase J.-M. Frécaut (1985: 115-143).

${ }^{49}$ Luciano, Lucio o el asno, 13. Trad. J. L. Navarro

${ }^{50} \mathrm{Cf}$. Apuleyo, III, 22-23.

${ }^{51}$ Cf. Odisea, X, 240.

${ }^{52}$ Cf. Ovidio, Met. XIV, 223 ss.

${ }^{53}$ Ovidio especifica que, a Macareo, en lugar de palabras, tan sólo le era posible emitir un ronco murmullo: pro uerbis edere raucum/ murmur ( Met. XIV, 280-281)

${ }^{54}$ Cf. Ovidio, Met. I, 584 ss.
} 
desgracias $»^{55}$. Finalmente recuperó su figura humana. Sólo entonces, dice Ovidio, «vuelve a ensayar tímidamente el interrumpido uso de la palabra» ${ }^{56}$. Otro tanto le ocurrió a Calisto, una muchacha del cortejo de la diosa cazadora Ártemis, que, seducida por Zeus, vino a convertirse, por obra de la diosa, en un animal. Sus antiguos sentimientos, señala Ovidio, «permanecen en ella incluso después de convertida en osa, y atestiguando por sus constantes gemidos sus angustias levanta al cielo y a los astros las manos conforme las tiene, y piensa, aunque no puede decirlo, que Júpiter es un ingrato.» ${ }^{57} \mathrm{El}$ padre de los dioses, finalmente, la convirtió en constelación, la que recibió el nombre de $\mathrm{Osa}^{58}$. El cazador Acteón, en fin, fue transformado en ciervo, no por un crimen, sino por una «falta de la Fortuna $~^{59}$ : había visto involuntariamente la desnudez de la diosa Diana. Cuando Acteón, una vez transformado, contempló su rostro en el agua, tampoco pudo articular palabra. Un gemido fue su lenguaje, «unas lágrimas corrieron por un rostro que no era el suyo, y sólo su primitiva inteligencia le quedó «60. Sus perros, que no lo reconocieron, lo devoraron. De la misma manera, el protagonista de la obra de Luciano, tras haber sido convertido él mismo en asno, confiesa: «En todos los aspectos yo era un burro, pero en mis entrañas y mi mente seguía siendo aquel hombre, Lucio, con excepción de la voz» ${ }^{61}$. A estos personajes Ovidio sigue denominándolos en su poema con su nombre personal, y comparten otros elementos: acaban aceptando una nueva forma de alimento en consonancia con su nueva naturaleza animal y buscan el apoyo de sus allegados, con quienes intentan comunicarse, aunque en vano, ya que éstos no pueden comprenderles al no poder articular aquellos un lenguaje humano. El protagonista de la obra de Kafka, al principio de su transformación, también cambia la voz:

Gregor se asustó al oír su propia voz [...] pues aunque era, inconfundiblemente, la de siempre, salía como desde muy abajo y mezclada con un doloroso e irreprimible pitido que solo en un primer momento permitía oír con claridad las palabras, para luego, cuando resonaban, deformarlas de tal modo que uno no sabía si había oído bien ${ }^{62}$.

Más adelante, el gerente de la empresa en que trabaja Gregor, al presentarse en casa de la familia Samsa, dice: «¿Has oído cómo hablaba? Era una voz de animal» ${ }^{63}$. Ello no obsta para que sus padres y hermana sigan refiriéndose a él como Gregor, aunque él acabe encontrando tan solo su incomprensión. Así mismo rechaza la comida que su hermana le ofrece en una escudilla: «leche azucarada en la que nadaban rodajitas de pan

\footnotetext{
${ }^{55}$ Trad. Ruiz de Elvira: et gemitu et lacrimis et luctisono mugitul cum Ioue uisa queri finemque orare malorum. (Met. I, 732-733)

${ }^{56}$ Trad. Ruiz de Elvira: ... timide uerba intermissa retemptat. Ovidio, Met. I, 746.

${ }^{57}$ Trad. Ruiz de Elvira: Mens antiqua manet (facta quoque mansit in ursa),/adsiduoque suos gemitu testata dolores/ qualescumque manus ad caelum et sidera tollit/ ingratumque Iouem, nequeat cum dicere, sentit. Ovidio, Met. II, 485-488.

${ }^{58}$ La leyenda se remonta a Hesíodo (frag 163 Merkelbach-West). Cf. Eratóstenes, Catasterismos, 1 y 8, ed. J. Pàmias. Sobre las fuentes de la leyenda, véase Forbes-Irving (1992: 202-205).

${ }^{59}$ Fortunae crimen...non scelus (Ovidio, Met. III, 141-142).

${ }^{60}$ Trad. Ruiz de Elvira: ... uox nulla secuta est;/ingemuit; uox illa fuit, lacrimaeque per oral non sua fluxerunt; mens tantum pristina manet. (Ovidio, Met. III, 201-203).

${ }^{61}$ Luciano, Lucio o el asno, 15. Trad. J.L. Navarro.

${ }^{62}$ La Transformación, 1915, O.C. III, p. 89. Trad. J.J. del Solar B.

${ }^{63}$ Ibid. p. 97.
} 
blanco» ${ }^{64}$, para acabar aceptando una comida no apta para un ser humano: Sobre un periódico viejo, dice el narrador, ahora

...había verduras pasadas y medio podridas, huesos sobrantes de la cena, rodeados de una salsa blanca que se había endurecido, unas cuantas pasas y almendras, un queso que, dos días antes, Gregor había calificado de incomestible ${ }^{65}(\ldots)$ «Rápidamente y con lágrimas de satisfacción en los ojos fue devorando uno tras otro el queso, la verdura y la salsa; los alimentos frescos, en cambio, no le gustaron, ni siquiera podía soportar su olor... ${ }^{66}$

Sobre los seres transformados en animales que conservan sus pensamientos y sentimientos humanos, dice Frècaut: «nos hallamos en presencia, no de un individuo afectado por un desdoblamiento de personalidad, sino de un ser híbrido, medio hombre-medio animal, por ejemplo, y en rigor, un monstruo» ${ }^{67}$. Visto desde la otra cara: Se trata de híbridos $^{68}$ que no son ni animales ni hombres. Seres que tienen pensamientos y sentimientos humanos, pero no lenguaje para expresarlos, que tienen deseos, pero no cuerpo para realizarlos. ${ }^{69}$

Otro aspecto desde el que se pueden considerar las metamorfosis es el de la motivación que lleva al cambio. Para algunos personajes míticos, como Proteo ${ }^{70}$, el viejo dios marino que habitaba junto a las costas de Egipto, la fuente del cambio era su propio deseo $^{71}$. Para otros seres, la metamorfosis es una salida, una huída de su sufrimiento: La ninfa Dafne, perseguida por el dios Apolo, fue convertida graciosamente por la divinidad en el árbol del laurel ${ }^{72}$. En el caso de los infelices compañeros de Ulises y de Lucio, es una mala pasada, una «equivocación del deseo» la que acarrea la metamorfosis. En todos estos casos puede apreciarse la acción de fuerzas divinas en la ejecución del cambio. Este hecho configura al héroe sujeto a una metamorfosis como un ser dominado por potencias que le sobrepasan. Hay también en el caso de Gregor Samsa un poder extraordinario por el que es convertido en escarabajo y del que no puede sustraerse, pero que no es posible especificar, por lo que tampoco podemos saber la motivación de su metamorfosis, a no ser que obedezca a un «deseo inconsciente» $\mathrm{u}$ «oscuro» ${ }^{73}$.

Pero volvamos a las leyendas de Kafka y Nicandro. Asentado el principal elemento común a ambas metamorfosis -el paso de dos seres humanos a insectos, uno descrito con precisión entomológica, otro más abstracto e indefinido-, y dejando aparte la abismática diferencia estilística que media entre el relato de un autor tocado por la genialidad y una leyenda tradicional sin pretensiones literarias; puesta al margen también la diferencia en-

${ }^{64}$ Ibid. p. 105

${ }^{65}$ Ibid. p. 107.

${ }^{66}$ Ibid. p. 108.

${ }^{67}$ Frècaut (1985: 116)

${ }^{68}$ A Kafka le atraían los seres híbridos. Recordemos su breve relato titulado Un cruzamiento, cuyo protagonista es un animal, mitad cordero, mitad gato, y su fascinación por las sirenas en el titulado El silencio de las sirenas.

${ }^{69}$ Cf. Salmerón (1999: 29).

${ }^{70} \mathrm{Cf}$. Odisea, IV, 349 ss.

${ }^{71} \mathrm{El} \mathrm{deseo,} \mathrm{al} \mathrm{menos} \mathrm{cuando} \mathrm{es} \mathrm{consciente,} \mathrm{incita} \mathrm{a} \mathrm{la} \mathrm{imitación,} \mathrm{la} \mathrm{candidata} \mathrm{a} \mathrm{las} \mathrm{metamorfosis,} \mathrm{Cf.} \mathrm{Brunel}$ (1974: 29).

${ }^{72}$ Cf. Ovidio, Met. I, 452-582.

${ }^{73}$ Cf. Brunel (1974: 27). 
tre un personaje con conciencia de su metamorfosis, un personaje nítidamente humano (aunque al mismo tiempo verdadero animal) frente a un relato como el de Cerambo, en el que tan sólo se nos dice que un hombre ha sido convertido en escarabajo, sin que sepamos de él pensamientos, sentimientos y demás, pasemos ahora a considerar los parecidos y diferencias entre ambos relatos en lo que se refiere a un aspecto fundamental: el paso de hombres a animales. ¿Cuál es desde esta perspectiva la diferencia esencial que gravita sobre la estructura de ambos relatos? Evidentemente, la relación entre culpa y castigo, simbolizadas por medio de las metamorfosis. Es conveniente, pues, ahondar, en primer lugar, en la significación profunda que entraña, en la Mitología y la Literatura, el paso de un ser humano a un ser animal así como sus consecuencias. Fue el filósofo G.W.F. Hegel quien, en sus Lecciones de Estética, al considerar el simbolismo consciente (aquel en el que lo espiritual se expresa mediante una clara separación de forma y contenido), y en concreto, al encarar las comparaciones del arte donde se comienza por lo exterior (como es el caso de la fábula, la parábola, el refrán o el apólogo) alumbró de manera magistral el género de las metamorfosis. Las metamorfosis (tal como podemos seguir en los relatos de época clásica, y, especialmente en época helenística y Ovidio) son, precisamente, las formas simbólicas que señalan de manera más clara la separación entre el espíritu y la naturaleza, ya que el paso de hombre a animal contiene la significación profunda de un castigo o de una caída de existencias espirituales en existencias naturales. En las metamorfosis no se aprecia ya, como entre los egipcios antiguos, lo divino «en la cerrada y misteriosa interioridad de la vida animal $»^{74}$, sino que ahora, a partir de la devaluación del reino animal a la que se ha llegado en época de los griegos (seguramente por hallarse éstos ya en un estadio en que los animales han sido dominados y domesticados), los seres sujetos a metamorfosis «pierden la libertad de la vida espiritual y se convierten en una existencia puramente natural ${ }^{75}$. De esta manera las metamorfosis, en su paso de hombre a animal, contienen frente a la naturaleza (en su aspecto moral) la orientación negativa que lleva a hacer de lo animal y de otras formas inorgánicas una figura de la degradación de lo humano ${ }^{76}$. Esta degradación se debe a una causa: un crimen, un delito, un mal paso, una desgracia. A causa de ello, los personajes caen en una culpa o dolor infinitos y son convertidos en animales. Este hecho sirve entonces para articular el simbolismo reflexivo: Cerambo no es ahora sólo un escarabajo, sino un escarabajo que recuerda en su forma y costumbres el delito de su vida anterior; el laurel, no es sólo un árbol, sino un árbol que recuerda una desgracia, una pena, como fue el triste final de Dafne tras la persecución de Apolo; el florecimiento primaveral del laurel (en griego daphné) es, por otra parte, una expresión de belleza que recuerda la bella figura de la muchacha. La metamorfosis de Cerambo obedece al castigo que se sigue de una culpa. En Kafka, una vez más, vemos su reverso: la caída que supone, sin una causa definida, la metamorfosis de Gregor convierte toda la cotidianeidad de su vida en una culpa indefinida. Es éste uno de los temas más esenciales y recurrentes en la obra de Kafka, la relación no recíproca entre culpa y castigo. La palabra alemana Schuld -se ha señalado oportunamente ${ }^{77}$ - significa al tiem-

\footnotetext{
${ }^{74}$ Hegel (1836-1838) I, p. 346; cf. p. 315.

${ }^{75}$ Hegel, o.c. I, p. 346.

${ }^{76}$ Cf. Hegel, o.c. II, pp. 29-33.

${ }^{77}$ Por ejemplo, E. Barjau en su introducción a la traducción al catalán de J. Fontcuberta de La Transformación: La Metamorfosi, Barcelona 1997, pp. XVI-XVII.
} 
po culpa y «pago de la culpa», cuenta, factura, castigo. Kafka, quien experimentó en su vida un «infinito sentimiento de culpabilidad» ${ }^{78}$, invierte este proceso: describe el castigo, señala el sentimiento de culpa, pero no dice su causa ${ }^{79}$. Por lo demás, en las metamorfosis clásicas son los dioses quienes ejercen el poder en las metamorfosis ${ }^{80}$; en Kafka, el poder que lleva al protagonista a sufrir una metamorfosis culpable y dolorosa es una fuerza misteriosa e innominada, contra la que el protagonista lucha, aunque no pueda liberarse.

Gustav Janouch, el joven amigo y confidente de Kafka, ha dejado un vivo testimonio del particular modo en que el autor de La Transformación entendía la degradación que conlleva el paso de hombre a animal. Cuenta en sus Conversaciones con Kafka ${ }^{81}$ que, en cierta ocasión, le llevó a nuestro autor un libro cuyo tema era el de una mujer convertida en zorra ${ }^{82}$, creyendo advertir, en estado de alarma, un plagio de la obra maestra de Kafka, quien entonces le respondió:

No, no, eso no lo ha sacado de mí. Es algo que flota en el ambiente de estos tiempos. Los dos hemos trascrito de nuestra propia época. El animal nos resulta más próximo que el hombre. Ahí están las rejas ${ }^{83}$. El parentesco con el animal nos resulta más fácil que con los seres humanos $^{84}$.

Es evidente que la posición del hombre con respecto a los animales en la obra de Kafka no está idealizada, más bien, difumina el hiato establecido entre ambos. Aunque reconoce que escribir como una moda sobre los animales «es la expresión por la nostalgia por una vida libre y natural», al modo rousseauniano, distingue explícitamente este hecho del verdadero aspecto que se esconde detrás: «para un hombre -dice- la vida natural es vivir en cuanto ser humano. Pero nadie se da cuenta de ello. Nadie quiere verlo así. La existencia humana es demasiado penosa, por eso se la quiere eludir al menos en el terreno de la imaginación». No se vuelve a la Naturaleza tras la huella de una vida libre y natural, se regresa al mundo animal porque resulta mucho más fácil que la existencia humana. $\mathrm{Y}$ en un tono nietzscheniano, añade:

${ }^{78}$ Así lo dice expresamente en la Carta al padre.

${ }^{79}$ La palabra alemana Schuld proviene de la raíz indoeuropea *(s)kel-, que significa «cortar», «golpear», «pinchar», y también «hacer escisiones»; también, «ser culpable»; cf got. Skulan (schuldig sein). El latín scalpo, -ere, y sculpo, significan «esculpir», «cincelar» [tal vez el nombre del dueño en el esclavo]. Cf. J. Pokorny, s.u. * $(s)$ kelp y *skelp $(e)-p$ - . En el relato de Kafka titulado En la colonia penitenciaria, una máquina de castigo graba, sobre la piel del condenado, el nombre del delito.

${ }^{80}$ Sobre la relación entre poder y metamorfosis, véase Canetti (1960) II, pp. 333-381.

${ }^{81}$ Janouch (1997: 59-61).

${ }^{82}$ Se trata de la novela Lady into fox, Dama en zorro (1923) del autor inglés David Garnett (1892-1981). Según Borges (O.C. IV, Ed. Emecé, p. 264), este relato «importa una total renovación del género fantástico», pero se diferencia de la obra de Kafka en «todo contacto con el clima peculiar de las pesadillas».

${ }^{83} \mathrm{El}$ artista es, para Kafka, «un pájaro de colores más o menos brillantes encerrado en la jaula de su propia existencia» (...) «Yo soy un pájaro muy impresentable. Soy un grajo, un kavka. (...) Desconcertado, voy dando saltitos entre los hombres, que me miran llenos de desconfianza. Al fin y al cabo, soy un pájaro peligroso, un ladrón, un grajo. Aunque sólo en apariencia. En realidad carezco de sensibilidad para los objetos brillantes. Por eso ni siquiera luzco unas relucientes plumas negras. Soy gris como la ceniza. Un grajo que anhela pasar desapercibido entre las piedras. Cf. Janouch, o.c., pp. 51-52. Salmerón traduce «graja». Sobre la diferencia entre «cuervo», «chova», «grajo», etc, véase su introducción, p. 27, n. 29

${ }^{84}$ Janouch, o.c. pp. 60-61. La cursiva es nuestra. Cf. Salmerón, o.c., pp. 28-30. 
Bien arropado por el rebaño, el hombre actual desfila por las calles de la ciudad en dirección al trabajo, al pesebre y a la diversión (...) No hay maravillas sino instrucciones de uso, formularios y normativas. A la libertad y a la responsabilidad se les tiene miedo. Por eso el hombre prefiere ahogarse detrás de las rejas que él mismo se ha fabricado. ${ }^{85}$

Una vez reducidas en Kafka las diferencias entre hombres y animales, el paso del uno al otro no resulta vertical, sino horizontal; no subraya tanto el paso a lo otro, como el desplazamiento en lo mismo. Walter Benjamin lo ha dicho ${ }^{86}$ con graciosa elegancia:

Ser animal no significaba para él [Kafka] sino haber renunciado por una especie de pudor a la figura y a la sabiduría humanas. Igual que un caballero distinguido, que se equivoca de bar, renuncia por pudor a limpiar su vaso.

Pero el «más difícil todavía», el «triple salto mortal» de Kafka es el que encontramos en dos breves relatos, Un informe para una academia y El nuevo abogado, ambos publicados en 1917, donde las metamorfosis se extienden de animal a ser humano. En el primer caso se trata de un mono que evoluciona rápidamente a hombre. Su proceso de conversión comienza con el uso del lenguaje, según explica en un Informe a una Academia Científica. En él nos cuenta que su nombre es Peter, y que, cuando tenía la condición de simio, fue capturado en Costa de Oro; sus cazadores le asignaron el sobrenombre de El Rojo. Cuenta también que, cuando era transportado en una jaula a la 'civilización', no trataba de encontrar la libertad, sino que tan sólo trataba de buscar una salida (de dudosa ganancia, como se verá) a la situación nada halagüeña en que se encontraba. Este deseo de encontrar, no la libertad (Freiheit) sino una salida (Ausweg) (el caso inverso de Dafne, quien sólo halló una salida mediante la metamorfosis que le otorgaron los dioses al huir, cuando intentaba salvaguardar su libertad), le convierte, culminado el proceso, en otro ser: un hombre que observa con lejanía su anterior vida simiesca. La disyuntiva que se le presenta a Peter es: o morir o sobrevivir, pero en este caso, a costa de transformarse en otro:

La renuncia a toda obstinación fue justamente el mandamiento supremo que me impuse; yo, mono libre, me sometí a ese yugo; [...] Al principio, de haberlo querido los hombres, aún habría podido regresar a través del gran portón que forma el cielo sobre la tierra, pero a medida que mi fustigada evolución progresaba, el portón se volvía cada vez más bajo y más estrecho; me fui sintiendo mejor y más anclado en el mundo de los hombres; el vendaval que desde mi pasado soplaba sobre mí se ha ido calmando; hoy es solo una corriente de aire que me refresca los talones; y ese agujero remoto por el cual ese aire llega y por el que yo mismo llegué un día se ha vuelto tan pequeño que, aunque tuviera la fuerza y la voluntad suficientes para regresar hasta él, me acabaría arrancando la piel del cuerpo al atravesarlo. ${ }^{87}$

${ }^{85}$ Janouch, o.c. pp. 61-62.

${ }^{86}$ Benjamin (1938: 207-208).

${ }^{87}$ O.C. III, p. 216. Trad. J.J. del Solar B. La imagen del paso ancho o estrecho, según las circunstancias, es muy antigua en la tradición hebrea: En Sem Tob, el judío de Carrión (s.XIV) leemos: «Farían dos amigos/ çinta de un anillo/ en que dos enemigos/ non metrién un dedillo» (Harían dos amigos cinturón de un anillo en que dos enemigos ni un dedo chico meterían» (vv. 249-252, ed. García Calvo). La misma imagen se halla en un poema secular de ibn Gabirol: La sortija que estuvo en mi mano antes por ceñidor y cinto me sirve ahora, (Selomo 
Siempre se ha considerado un modo de diversión contemplar a un animal remedando al hombre. En las obras de Luciano y Apuleyo podemos asistir a la exhibición de Lucio, convertido en asno, en un circo. En la novela, los espectadores lo ven como un animal que imita al hombre; el lector como un hombre encerrado en el cuerpo de un animal. Pero, Rafael Sánchez Ferlosio ha sabido ver ${ }^{88}$ el aspecto inquietante que se esconde en este tipo de espectáculos en los que se establece una semejanza entre simios y humanos. Para Ferlosio, el simio es «el extraño próximo (...) el testimonio fronterizo estratégicamente situado en el lugar preciso en que la naturaleza puede volvérsenos inquietante y agresiva»; se trata de algo percibido no sólo en la semejanza de forma o conducta, sino refrendado hoy día por el desciframiento del genoma humano (el orangután comparte el 96'4\% de sus genes con el hombre; el chimpancé el 98'4\%). La sistemática degradación a la que se somete a estas criaturas en el circo o en el espectáculo de variedades (Peter trabaja en un Cabaret) hace que aparezcan como «una especie de humanidad degenerada y caricaturesca» ${ }^{89}$; se pretende con ello exorcizar los inquietantes parecidos por medio de un perverso juego del tipo: cuanto más parecidos, más diferentes. ¿Cómo se consigue? Dice Ferlosio:

Poniéndola [la naturaleza] en ridículo -visto que se resiste a ser negada-, mediante el expediente de acogerla como una pretensión de identidad, y desplazando arteramente la comparación, del terreno biológico- en que se lo compararía con el hombre como especie animal- al ilegítimo terreno en el que queda contrastado con un hombre histórico concreto -precisamente aquel que como «el hombre» se pretende absolutizar-, como un hombre vestido, vestido incluso, según la última moda ${ }^{90}$.

La ridiculización, en último caso, pretende «escamotear cuanto amenace hacernos caer en la extrañeza». Pero el relato de Kafka da una vuelta a este mecanismo. El lenguaje de Peter, el simio-hombre, es específico y clarividente, y sirve, sobre todo, para poner de manifiesto la degradada naturaleza humana. Es ahora el hombre el que es puesto en la picota, porque el hombre se somete a la asimilación -pensemos en el judío de la Europa de finales del XIX y principios del XX-; es el hombre el que sigue la conducta del simio, el que renuncia a su libertad a cambio de una salida. Vemos ahora al hombre en el simio que ingresa en la comunidad humana trabajando dócilmente en un Cabaret. El filósofo Gustavo Bueno ${ }^{11}$ ha establecido la diferencia entre simios y personas humanas no en razones genéticas, ni en la pretendida racionalidad del hombre con respecto a las bestias, sino en las relaciones que el hombre ha establecido frente a los animales: el poder, la dominación, el control. Al haber establecido en la época moderna los hombres entre sí fé-

\footnotetext{
Ibn Gabirol, Poesía secular, ed. Elena Romero, Madrid, Alfaguara 1978). El círculo demasiado estrecho como metáfora de lo imposible, se encuentra ya en el Nuevo Testamento: «Más fácil es que un camello pase por el ojo de una aguja que un rico entre en el reino de Dios» (Mt. 19.24, Marcos 10.25 y Lucas 18.25). Quizá pudiera leerse, en vez de kámelos, «camello», kamílos, «cable, cordaje grueso» (cf. Suidas y escolio a Aristófanes, Avispas 1030) confundido en la pronunciación itacista). Podemos entrever a los dos amigos (o enemigos) de los versos de Sem Tob en el desdoblamiento del personaje del simio en Un Informe para una academia.

${ }^{88}$ Sánchez Ferlosio (1966: 11-46).

${ }^{89}$ Ibid., p. 31.

${ }^{90}$ Ibid., p. 32

${ }^{91}$ G. Bueno (2006).
} 
rreas relaciones de asimilación y dominio (precisamente los elementos que distinguen a personas humanas de animales), al perder su libertad, las diferencias específicas entre el género animal y el género humano quedan reducidas. Kafka consigue en su relato, una vez difuminadas las diferencias entre hombres y simios, que asistamos a la elevación del simio al hombre con un sentimiento de decadencia. Que podamos decir, en un sentido insólito, que «el hombre desciende del mono».

El protagonista del relato El nuevo abogado ${ }^{92}$ es Bucéfalo, el legendario caballo de Alejandro Magno, quien, en una época que se revela como el ocaso de la grandiosidad de la Historia y la Mitología, acude, en forma humana, como nuevo abogado, a su trabajo en la oficina, su nuevo campo de batalla. Pocos reparan allí en su nueva figura; tan sólo un ujier, cuando Bucéfalo «levantando muy alto los muslos subía escalón por escalón haciendo resonar el mármol bajo sus pasos». En la oficina, lejos ya de los fastos que le acompañaban en su esplendoroso pasado, sin la grandeza de un jinete que fuera capaz de señalar el camino hacia la India, haciendo de la necesidad virtud, se entrega a aquello que cree le reportará un mayor provecho: enfrascarse en la lectura de los libros de Derecho y de la tradición. Si en el fabuloso mundo de los orígenes míticos el engrandecimiento a través de una metamorfosis estaba reservado a personajes privilegiados como los héroes, que llegaban a ser dioses, o en los albores del siglo XX, tras el darwinismo, el hombre tenía de sí mismo una consideración más noble que la de un ángel caído, pues se consideraba a sí mismo un animal ascendido, en el relato Un nuevo abogado puede percibirse, paradójicamente, a través del paso de un animal a un hombre, una sensación contraria: la de degradación y decadencia, el descenso del hombre, inserto ahora en una nueva vida nada heroica, sino, más bien, mediocre y gris, como aquella que sobrelleva el doctor $\mathrm{Bu}-$ céfalo en su puesto de trabajo. En ambos relatos, en las dos originales historias de metamorfosis de animales que llegan a ser hombres, puede apreciarse el principio de contradicción que encierran, y puede comprobarse de manera esencial una de las sentencias más misteriosas de Heráclito, el sabio de Éfeso: «Camino arriba y camino abajo es uno y el mismo» ${ }^{93}$.

Volvamos una vez más a la leyenda de Cerambo. Ésta pertenece a la Mitología. Los relatos de Kafka a lo que llamamos ficción. Antonio Ruiz Elvira distingue mito o leyenda («todo relato de sucesos que son inciertos e incomprobables, pero sobre los cuales existe una tradición que los presenta como realmente acaecidos» ${ }^{94}$ ) y que como tal son aceptados o rechazados, de ficción («invención libre que equivale a certeza de no ser cierto lo que ella cuenta» $)^{95}$. Una primera diferencia entre los dos relatos reside, pues, en el carácter tradicional de aquella frente al carácter de autor de ésta. Pero mito y ficción comparten no certeza, y al mismo tiempo, pretensión de veracidad. Tanto la mitología como la ficción pertenecen, además, frente a la estricta realidad y certidumbre de la Historia, al reino general de la posibilidad, en una escala que va de mayor a menor verosimilitud, de menor a mayor fantasía.

La escritora Carmen Martín Gaite ha acuñado la expresión «brecha en la costumbre» a la hora de describir el concepto «fantástico»:

\footnotetext{
${ }^{92}$ O.C. III, p. 179. Trad. J.J. del Solar B.

${ }^{93}$ Heráclito, frag. 60, ed. García Calvo.

${ }^{94}$ Ruiz de Elvira (1975:7).

${ }^{95}$ Ibid., p. 11.
} 
...algo que nos sorprende y rompe nuestros esquemas habituales de credibilidad y aceptación, un descubrimiento, a veces banal y fortuito, pero que provoca -y eso es lo importanteun nuevo punto de vista, un impulso sin control, una perplejidad, algo, en fin, que llama nuestra atención con guiños inhabituales, invitándola a salir de su letargo; algo que transforma nuestra percepción del mundo -como si se miraran las cosas por su revés- y que exige una interpretación ${ }^{96}$.

Buscando la definición más estricta, Tzvetan Todorov, en su Introduction à la littérature fantastique, considera la duda como la piedra de toque del género: «Lo fantástico -dice- es la duda (hésitation) experimentada por un ser que no conoce más que las leyes naturales cuando se enfrenta con un suceso de apariencia sobrenatural». Pero Todorov define otros subgéneros: lo extraño, si el fenómeno extraordinario o sobrenatural se explica por una ilusión de los sentidos o como un producto de la imaginación, y lo maravilloso, si el fenómeno se mantiene como verdadero, como parte de la realidad, pero explicado por leyes sobrenaturales o desconocidas ${ }^{97}$. Los relatos de Cerambo, de Apuleyo o de Kafka se insertarían en esta última categoría: En el primer caso son los dioses quienes operan el prodigio. En el segundo se habla de «la fuerza misteriosa de los seres sobrenaturales ${ }^{98}$. Las metamorfosis en la obra de Kafka, en fin, se realizan «merced a una fuerza ultraterrena y sobrehumana $\gg{ }^{99}$ que no se especifica ni se comprende. Se trata de una fuerza que «transforma al ser humano tan recónditamente que la norma de vida acostumbrada ya no puede ofrecer una seguridad» ${ }^{100}$. Ahí es donde el hombre, caído en la metamorfosis de lo extraño, queda expuesto a un extremo sufrimiento, que con frecuencia es la antesala de la muerte ${ }^{101}$. En La Transformación se descarta expresamente lo extraño («no era un sueño, no...» dice el narrador al principio de la metamorfosis). Pero, en el curso del relato, a diferencia de los relatos en que lo maravilloso va calando poco a poco sobre la esfera de lo real en el relato, Kafka, una vez más da la vuelta al proceso: Parte del hecho maravilloso (la conversión en escarabajo) para ser tratado cada vez de un modo más natural, llegando incluso al extremo realismo ${ }^{102}$. Jordi Llovet lo dice con palabras certeras:

En este relato, todo parece estar pensado de tal modo que lo extraño, lo sobrenatural o lo fantástico se halle como quien dice en la periferia de la narración, en un exterior caliginoso e inconcreto que arremeterá, eso sí, contra los hábitos decodificadores de los lectores, en general poco acostumbrados -salvo que sean asiduos lectores de Kafka- a no poder discernir con nitidez la línea que separa entre sí lo real, lo verosímil y lo fantástico. ${ }^{103}$

\footnotetext{
${ }^{96}$ Carmen Martín Gaite, «Brechas en la costumbre», Diario 16, 17-XI-1990.

97 Todorov (1970:46 ss)

${ }^{98}$ Apuleyo, I, 10.

${ }^{99}$ Cf. Falk (1961:138)

${ }^{100}$ Ibid.

${ }^{101}$ Ibid., pp. 127-141.

${ }^{102}$ Cf. Todorov, o.c.pp. 177-184.

${ }^{103}$ OC.III, p. 1003.
} 


\section{BIBLIOGRAFÍA}

ANTONINo Liberal. Metamorfosis, Introducción, traducción, notas y comentarios de José Ramón del Canto Nieto, 2003, Madrid, ed. Akal.

Apuleyo, Lucio. Las Metamorfosis o El Asno de Oro, Introducción, texto, traducción y notas de Juan Martos, 2003, Madrid, 2 vol. CSIC.

—, El asno de oro, Introducción, traducción y notas de Lisardo Rubio, 1978, Madrid (3ª reimp. 1995), ed. Gredos.

BENJAMIN, Walter (1938). «Dos iluminaciones sobre Kafka», en Iluminaciones I, pp. 197-221, 1971, Madrid, trad. J. Aguirre, ed. Taurus.

Bonnefoy, Yves (ed) [1981]. Diccionario de las mitologías (vol. II), trad. J. Pòrtulas y M. Solana, 1996, Barcelona, ed. Destino.

Bousoño, Carlos (1976). Teoría de la expresión poética I, Madrid, ed. Gredos.

BRUnel, Pierre (1974). Le mythe de la Métamorphose, París, ed. Armand Colin.

BuENo, Gustavo. «Por qué es absurdo «otorgar» a los simios la consideración de sujetos de derecho». El Catoblepas (51) 2006, www. nodulo.org/ec/2006/n051.htm

CANETTI, Elías. Masa y poder [1960], trad. H. Vogel, 1983, Madrid, ed. Alianza, 2 vols.

—, El otro proceso de Kafka [1968], en La conciencia de las palabras (pp.100-215), trad. J.J. del Solar B, 1982, México, ed. FCE.

FaLK, Walter (1961), Impresionismo y expresionismo. Dolor y transformación en Rilke, Kafka, Trakl, Salzburgo, trad. M. Bueno, Madrid 1963, ed. Guadarrama.

Forbes Irving, P. M. C. Metamorphosis in Greek Myths, 1992, Oxford, Claredon Press.

FRÉCAUT, Jean Marc. «Un thème particulier dans les Métamorphoses d'Ovide: le personnage métamorphosé gardant la conscience de soi (Mens antiqua manet: II, 485)», Journées Ovidiennes de Parménie, Latomus 1985, vol. 189, pp. 115-143.

GIL, Luis (1959). Nombres de insectos en griego antiguo, Madrid, CSIC.

Gow, A. S. F. y SCHOLFIELD, A. F. (1953). Nicander. The poems and poetical fragments, Cambridge.

Hegel, G. W. F. (1836-1838). Lecciones de Estética, trad. R. Gabás, 1989, Barcelona, 2 vols, ed. Península.

JANOUCH, Gustav (1968). Conversaciones con Kafka, trad. Rosa Sala, 1997, Barcelona, ed. Destino.

KAFKA, Franz. Obras completas, ed. J. LLovet, 1999-2003, Barcelona, varios volúmenes, ed, Galaxia Gutemberg - Círculo de lectores.

Llovet, Jordi (1990). Franz Kafka. Bestiario, Barcelona, ed. Anagrama.

Luciano. Lucio o el asno, en Obras, trad. J.L. Navarro, 1988, Madrid, ed. Gredos.

Martín Gaite, Carmen. «Brechas en la costumbre», Diario 16, 17-XI-1990.

NАвоKоv, Vladimir. «Comentario sobre La Metamorfosis», en Franz Kafka. La metamorfosis (pp. 105-144), 1986, Barcelona, ed. Círculo de lectores.

Ovidio. Metamorfosis, edición y traducción de A. Ruiz de Elvira, 1964, CSIC.

PAPATHOMOPOUlos, Manolis (1968). Antoninus Liberalis. Les Métamorphoses, edición y traducción al francés, París, Les belles lettres.

POKORNY, Julius. Indogermanisches etimologisches Wörterbuch, I, Berna 1959.

RUIZ DE ElviRA, Antonio (1975). Mitología clásica, Madrid, reimpr. 1984, ed. Gredos.

SALMERón, Miguel (1999). Franz Kafka. La metamorfosis y otros relatos de animales, introducción y traducción, Madrid, Colección Austral.

SÁnCHEZ Ferlosio, Rafael (1972). Prólogo a Las aventuras de Pinocho, Madrid, Alianza.

—, (1966), «Personas y animales en una fiesta de bautizo» en Ensayos y Artículos, I, pp. 11-46, Barcelona 1992, ed. Destino.

Todorov, Tzvetan (1970). Introduction à la littérature fantastique, París, ed. du Seuil. 